\title{
Designing Pro-Competitive Research Data Pools: Which EU Competition Remedies for Research Data Silos in Digital Markets?
}

\author{
by
}

\author{
Giulia Schneider*
}

\section{CONTENTS}

I. Introduction and outline

II. European policy perspectives on data sharing

III. Data sharing, data pools and data silos

IV. Information accumulation and information-based remedies in high technology markets

1. Introduction

2. Sharing Obligations under Article 102 TFUE

3. The divestment of research pools in merger procedures

V. Can information-based remedies be applied to data silos?

1. Introduction

2. The theoretical perspective and digital markets' specificities

3. The operational perspective and the relevance of data protection law 3.1. Opening remarks

3.2. The collaborative governance of data sharing remedies

VI. Conclusions

\section{Abstract}

The study moves from the assumption that the sharing of data can - under specific circumstances - give rise to anticompetitive aggregations of research-valuable data in the form of closed data silos. It addresses the question whether and how competition

* Dr. Giulia Schneider ( $\mathrm{PhD}$, Bocconi University) is postdoctoral researcher at Sant'Anna School of Advanced Studies (Lider Lab Research Centre) in private comparative law; e-mail: schneidergiulia@yahoo.it; ORCID: 0000-0002-6244-717X

Article received: 11 March 2020, accepted: 30 May 2020. 
remedies available under EU law can be used for the design of pro-competitive data pools in digital markets. Interesting suggestions for these purposes are given by the recent enforcement policies enacted by the European Commission in high technology innovation markets. Although aimed at restoring very different anticompetitive conducts, these remedies nonetheless appear to share the common function of opening up established innovation alliances for the transfer of research-valuable information assets to external competing parties. Against this backdrop, the suitability of such information-based remedies in the context of digital markets is questioned. The study ultimately puts forward the opportunity of a close collaboration between competition and data protection authorities for a joint governance of data sharing remedies.

\section{Resumé}

Létude part de l'hypothèse que le partage des données peut - dans des circonstances spécifiques - donner lieu à des agrégations anticoncurrentielles de données précieuses pour la recherche sous la forme de silos de données fermés. Elle aborde la question de savoir si et comment les remèdes en matière de concurrence disponibles en vertu du droit communautaire peuvent être utilisés pour la conception de pools de données proconcurrentiels sur les marchés numériques. Des suggestions intéressantes à cet égard sont données par les récentes politiques de mise en œuvre adoptées par la Commission européenne sur les marchés de l'innovation de haute technologie. Bien qu'elles visent à rétablir des comportements anticoncurrentiels très différents, ces mesures correctives semblent néanmoins partager la fonction commune d'ouvrir les alliances d'innovation établies pour le transfert d'actifs d'information précieux pour la recherche à des parties concurrentes externes. Dans ce contexte, la pertinence de ces mesures correctives fondées sur l'information dans le contexte des marchés numériques est remise en question. L'étude met finalement en avant l'opportunité d'une collaboration étroite entre les autorités de la concurrence et de la protection des données pour une gouvernance commune des mesures correctives en matière de partage des données.

Key words: abuse; collaborative governance; data sharing; data silos; merger.

JEL: K21

\section{Introduction and outline}

Data represent a highly scientifically valuable asset, the accessibility and the processing of which is becoming ever more essential for research and market innovation purposes in digital markets. The interactions between various market players, specifically designed for the pooling together of different types of research valuable data, appear to have increased, creating a networked digital innovation environment. 
However, the free flow of data, both between private businesses and between private businesses and public institutions, as enabled and promoted by European policy initiatives within the Digital Single Market Strategy, cannot be left to the digital free market play. As has been acknowledged, the unrestricted flow of information could create legal uncertainty, negatively affecting not only the data subjects, who are the originators of these data, as well as the consumers'/patients', who ultimately come to use the resulting digital products and services, but also the same 'merchants' of these sensitive data (Graef, Husovec and Purtova, 2018). These concerns have been upheld by Commissioner Vestager, stressing how the European Commission welcomes the pooling of data 'as long as companies do it in a way that protects people's privacy and doesn't hurt competition' (Vestager, 2016).

Accordingly, the great emphasis, placed at European policy level on the economic benefits of data pooling, is accompanied by a greater reflection on the regulatory tools needed for the creation of a digital research environment that does not jeopardize consumers' fundamental right to data protection and other businesses' economic freedoms and, in particular, their freedom to compete.

Against the backdrop of the developing debate, the present study moves from the assumption that the sharing of data can - under specific circumstances - give rise to anticompetitive aggregations of research-valuable data in the form of closed data silos. The enclosed nature of such data silos prevents fruitful information interactions among other market players, thus blocking the advancement of technological progress in digital markets.

The study focuses on 'research-valuable data', broadly intended as every digital data that has a specific scientific or technological value and is thus relevant for research and development purposes in various sectors of the digital economy (OECD, 2019). In digital markets, these datasets are mostly made up of personal data, which are of great competitive value (European Data Protection Supervisor, 2014; Autorité de la concurrence and Bundeskartellamt, 2016) and whose analysis, also in combination with other data, is extremely precious for innovation purposes (OECD, 2019). This study moreover deals with data pools, irrespective of their public or private nature. However, as will be demonstrated, the risk of the emergence of data silos, and resulting anticompetitive distortions, is greater in respect to privately accumulated data.

Under these premises, the study addresses the question whether, and how competition remedies available under EU law can be used for the design of pro-competitive data pools in digital markets. More precisely, it queries whether the EU competition law framework entails adequate tools for addressing the anticompetitive harms stemming from data silos, or whether, as recent literature has lately come to argue also (Crémer, Montjoye and Schweitzer, 2019), digital 
markets require the introduction of radically new legal reaction tools. The study ultimately shows that in respect to anticompetitive conducts stemming from data silos, traditional competition law sharing remedies developed both under Article 102 TFUE and under merger procedures in high technology markets may be applicable, with the need, however, to reconsider their governance in light of the very nature of the data from which the anticompetitive conducts, and the related anticompetitive harm, derive. In this perspective, the fact that in the digital economy competitively-relevant data is mostly personal data triggers some initial reflections over the opportunity of a closer collaboration of competition and data protection authorities in the administration of sharing remedies.

\section{European policy perspectives on data sharing}

Some European regulatory initiatives within the Digital Single Market Strategy promote the flow of data both between private businesses and between private businesses and public institutions. In this sense, data sharing has been growingly considered as a fundamental engine for the maximization of the 'growth potential of the digital economy', and of the efficient employment of data in the digital European economy (European Commission, 2018).

The free flow of information initiative has become a fundamental pillar in the development of the Digital Single Market Strategy. ${ }^{1}$ In this perspective, information interactions among stakeholders, of both public and private nature, are regarded as a key element in the creation of a European data space $^{2}$ (European Commission, 2017b).

Accordingly, the European Commission has also very recently stressed the importance of the sharing of privately-held data among businesses (B2B), of governmental data to businesses (G2B), of business data to governments (B2G), and ultimately among public authorities. The relevance of data sharing in these various forms has been placed at the heart of the latest European strategy for data (European Commission, 2020).

In the new strategy, the Commission reaffirms the importance to inform future regulatory and policy actions regarding data, upon the principle of 'as open as possible, as closed as necessary' (European Commission, 2020),

1 European Commission, Communication from the Commission to the European Parliament, the Council, the European Economic and Social Committee and the Committee of the Regions-Building a European Data Economy COM(2017) 9 final.

2 European Commission, Commission Staff Working Document on the Free Flow of Data and Emerging Issues of the European Data Economy, Accompanying the Communication Building a European Data Economy, SWD(2017) 2 final. 
which promotes data re-usability and analysis across different sectors of the economy.

Direct reflections of these policy statements at European regulatory level are given by the Regulation on the free flow of non-personal data ${ }^{3}$ and the Open Data Directive. ${ }^{4}$ Both regulatory frameworks indeed place particular emphasis on the importance of research data and their transferability for the ultimate purpose of creating the right market conditions for innovation. In particular, the two frameworks rely on the policy paradigm of open science and innovation, aiming to foster the interaction between research results and market innovation objectives. Specifically, the Open Data Directive requires Member States to establish facilitated access regimes regarding public data under its Article 10.

Conversely, in respect to private data, only specific access regimes are to be found, as the one envisaged under the Payment Service Directive ${ }^{5}$ in the internal market (PSD2), establishing an access regime regarding information related to the payment account under its Article 67. Also under the General Data Protection Regulation $^{6}$ (hereinafter: GDPR), both the right to data portability under Article 20 GDPR (Graef, Husovec and Purtova, 2018) and the research exemption under Article 89 GDPR (Schneider, 2019), have been associated by the literature with broader goals of data mobility among economic actors.

Beyond these specific access regimes, the sharing of private data among businesses (B2B) mainly relies on the same businesses' contractual freedom (Graef, Tombal and Streel, 2019). The recalled policy and regulatory framework suggests a growing attention by European regulators towards the opening up of businesses' and public stakeholders' collected datasets. However, if the latter are the object of specific accessibility policies, which Member States are required to set up in accordance with the Open Data Directive, the sharing of private data appears to be still largely left to free market play. Stated another way, most policy initiatives focus on public sector data, whereas the sharing

3 Regulation EU 2018/1807 of the European Parliament and of the Council of 14 November 2018 on a Framework for the Free Flow of Non-personal Data in the European Union, 28.11.2018, OJ L 303, 28.11.2018, p. 59-68.

4 Directive EU 2019/1024 of the European Parliament and of the Council of 20 June 2019 on Open Data and the Re-use of Public Sector Information, OJ L 172, 26.6.2019, p. 56-83.

5 Directive EU 2015/2366 of the European Parliament and of the Council of 25 November 2015 on payment services in the internal market, amending Directives 2002/65/EC, 2009/110/ EC and 2013/36/EU and Regulation (EU) No 1093/2010, and repealing Directive 2007/64/EC, OJ L 337, 23.12.2015, p. 35-127.

${ }^{6}$ Regulation EU 2016/679 of the European Parliament and of the Council of 27 April 2016 on the protection of natural persons with regard to the processing of personal data and on the free movement of such data, and repealing Directive 95/46/EC (hereinafter; General Data Protection Regulation), OJ L 119, 4.05.2016, p. 1-88. 
of private data still mostly resides on voluntary schemes (OECD, 2019). As a result, the risk of market distortions stemming from businesses' freedom to share or not to share relevant datasets is higher than in respect to public data.

Accordingly, the great emphasis, placed on the economic and societal benefits of data pooling, is currently accompanied by a greater reflection on the regulatory safeguards needed for the creation of a digital research environment, that does not jeopardize consumers' fundamental right to data protection and other businesses' freedom to compete. While the debate regarding needed data protection safeguards has been fostered substantially, the assessment of the competition concerns related to data sharing practices has caught the attention of relevant scholarly literature only recently (Kathuria and Globocnik, 2019; Graef, Tombal and Streel, 2019).

\section{Data Sharing, Data Pools and the Problem of Data Silos}

Data sharing practices as promoted at European level give rise to data pools resulting from the aggregation among different stakeholders of different informational assets. In this perspective, the innovation paradigm, upon which these information sharing activities reside, is of collaborative nature. It appears, however, to be set in between an individual research paradigm and an open access one: far from the idea of free sharing platforms of scientific information, the collaboration alliances arising from data sharing are designed for the purpose of combining technological assets among very few partners.

Pooling practices indeed primarily rely on the aggregation and the access to datasets by the involved partners, along the lines of what can be defined as a 'restricted' disclosure approach. This means that only the parties of the sharing agreement gain access to the pooled data, in this way creating a shared 'anticommons' space, specifically designed for data-driven research and innovation purposes.

Businesses' freedom to contract and thus to share their datasets with other market players, needs to be, however, assessed also from the opposite perspective of the same businesses' freedom not to contract, and not to share, their data with other competing or non-competing parties.

In these regards, it has been interestingly observed that the technological means improving access to research information, equally can be employed for inhibiting access 'in ways that were never before practical' (David, 2000).

In the 'free' data sharing environment, exclusions from access to data can occur both outside and within established data pools. In the first case, a party is denied access to enter an established data-driven research consortium, acting 
as a unique economic entity, as in the case of a joint venture or a merger. In the second case, the technological superiority of a company, in respect to other members of an established data pool, can trigger appropriation mechanisms regarding data that was initially available to all members of the same data pool. Such an 'appropriation problem' (Gardner, Ostrom and Walker, 1990) can arise when a party to the pool has stronger technological and legal means for protecting data, and the connected analytical technology, and thus prevents other members from accessing aggregated datasets.

In this case, new risks of 'takeovers' of informational assets by the more influent member of an established research consortium arise, engendering an outright collaboration collapse (Svetiev, 2007).

The two considered scenarios suggest how data sharing practices can, under specific circumstances, lead to data accumulation in the form of outright silos that prevent further data flows. In most cases, these data silos directly stem from the exploitation by economic parties of obstacles impairing data sharing. These obstacles can be both of legal and technical nature.

The legal obstacles are related to intellectual property rights protecting the same data and the related processing infrastructure, such as copyright, the sui generis database right and above all trade secret protection (Gervais, 2019). Among further legal obstacles, when datasets entail personal data, also data protection rules, as the principles of purpose limitation and data minimization established by the General Data Protection Regulation, can operate in practice as a strong limit to data accessibility and sharing (Graef, Tombal, Streel, 2019).

In this last respect, it has been illustrated that, in the data marketplace, dataintensive actors are giving rise to an outright battle for the exclusive exploitation of personal data available in the 'free' market zones (Purtova, 2015). Contractual agreements among economic actors are a key factor in this respect. In particular, they allow coordination among collaborators in order to gain control of different components of interdependent know-how (Hilty, 2018).

However, in view of the difficulties to make the collaborative and fastchanging digital environment properly adhere to intellectual property rights and contractual schemes, control over research-valuable resources is defined also on the basis of the practical and technical ability to exclude other market players from access to data (Purtova, 2015). In addition to legal measures, thus, also factual and technical measures are further relied on for the purposes of enclosing companies' research data silos (Hilty, 2018). The importance for these purposes of technical protection measures is to be rooted, on the one hand, in the legal uncertainty regarding the extent to which intellectual property tools such as copyright and the sui generis database right can effectively protect digital data, and, on the other hand, in the unclear allocation of claimed rights in the data market (Drexl, 2018). Thus technical measures of 
protection have both the effect of factually stretching the limitations on the scope of exclusivities set by the law and of factually controlling resources that would not be eligible of protection (Hilty, 2018).

Through technical protection measures, the more powerful market player obtains de facto control over personal data and thus raises competitors' costs of accessing collected datasets (Rubinfeld and Gal, 2017). These technical measures can be related to encryption, proprietary formats or access controls (Hilty, 2018), impeding access by third parties and in this way blocking interactions among stakeholders.

However, also persisting technical hurdles to data sharing can operate as indirect technical facilitators of data accumulation by businesses. In this respect, the lack of common standards regarding data formats and semantics constitutes a still largely unresolved obstacle to data interoperability and sharing (Rubinfeld and Gal, 2019). The so far developed open data standards indeed regard primarily public data. ${ }^{7}$

Through the mentioned legal and technical tools, access to research valuable resources might thus be restricted by few data gathering entities, in a technological context 'that might be otherwise ripe for competitive innovation' (Bamberger and Lobel, 2017). The enclosed nature of the resulting data silos indeed prevents fruitful information interactions with and among other, in many cases contractually weaker, market players. This negatively impairs technological progress in those sectors for which the inaccessible digital data represent an essential research asset.

In this perspective, although leading to innovation-fruitful data pools, data sharing practices can also lead to the opposite reality of the fragmentation of existing datasets into enclosed data silos, generating threatening market imbalances, which have the effect of excluding smaller companies or weaker public research institutions from access to needed data.

The acknowledgment of the possible emergence of 'collective' or 'individual' data silos in the context of data sharing practices, triggers the assessment of the anticompetitive effects arising from the establishment of closed aggregations of research-valuable data. The questions to be addressed in this perspective relate to the assessment of: i) which anticompetitive conducts can occur in the context of data sharing practices in case of the emergence of data silos, and ii) whether and which remedies are available under the EU competition framework for the re-establishment of pro-competitive data pools. In these last regards, the next paragraphs will investigate whether, in the context of data sharing practices, businesses' and other parties' freedom (not) to share their data with others can be limited at a competition enforcement level, through

7 See European Data Portal, The Open Data Standards Directory, available at https://www. europeandataportal.eu/en/news/open-data-standards-directory $(30.06 .2020)$. 
a specific data sharing obligation imposed by competition authorities onto infringing parties.

Interestingly, the consideration of the latest developments of European case law in high technology markets, both in the context of the abuses of dominant positions and in the context of merger procedures, suggests the emergence, in these same markets, of information-based remedies. As will be assessed below, these remedies consist of sharing obligations regarding information that is otherwise inaccessible to competitors. An enquiry over these informationbased remedies shows that these have precisely the function of advancing information sharing interactions between stronger market players and weaker parties. After having illustrated the countenance of these emerging remedies in the field of high technology markets, the next section of the paper questions their suitability for the purposes of addressing harms to digital innovation and the re-establishment of a level playing field among data-intensive innovators.

\section{Information accumulation and information-based remedies in high technology markets}

\section{Introduction}

Antitrust scholars have traditionally highlighted the risks entailed in information sharing practices between competitors or potential competitors. Information sharing indeed facilitates coordination between some firmscompetitors or not- on the market, which potentially impairs innovation and harms other market participants and/or consumers, and ultimately also the wider public interest (Svetiev, 2007).

These considerations are well reflected in CJEU case law in hightechnology markets. Here, the CJEU has interestingly dealt with conducts related to information accumulation either by a single dominant entity or by a newly merged entity. As the relevant case law shows, in the first hypothesis, information accumulation can lead to an abuse of a dominant position, occurring in the form of a refusal to license or, more generally, to supply data needed by a competitor for entering the innovation race. In the second case, mergers in information-intensive sectors, such as the pharmaceutical and the chemical market, have been scrutinized by the Commission for their negative impacts 'at the level of innovation efforts by the Parties and its competitors'. ${ }^{8}$

Under these premises, a closer look at the enforcement policies in these cases suggests that the Commission has initiated a set of information-based

${ }^{8}$ European Commission, Communication - Building a European Data Economy, para. 348. 
competition remedies exceptionally designed by the competition authority for the target of either dominant or merged entities. These remedies respectively attain to disclosure obligations regarding 'essential' information as a remedy to market abuses under Article 102 TFEU and obligations to divest research pools in the context of merger procedures.

Although aimed at restoring very different anticompetitive conducts, these remedies appear in both cases to be grounded in an occurred harm to competition in innovation stemming from the pooling of data and to share the common function of opening up established innovation alliances for the transfer of research-valuable information assets to external competing parties.

As will be demonstrated below, the analysis of these remedies, both as a reaction to abuses under Article 102 TFEU and as a 'structuring' tool of occurring mergers, reflects the emerging relevance of an information-based remedial paradigm, strictly related to innovation considerations, in European competition enforcement in high technology markets. This triggers, in turn, the reflection over the possible suitability of such sharing remedies in the context of digital markets, and thus the possible alignment of this developing line of competition enforcement with the wider European Commission strategy on data and the related goal of maximizing the scale of data sharing between companies.

\section{Sharing obligations under Article 102 TFUE}

Information aggregation can facilitate abusive conducts directly stemming from the informational advantage acquired through massive data collection (Graef, 2016). The competitive advantage stemming from the collection of technology-relevant information is indeed very likely to result in an informational 'super-dominance' or quasi-monopoly (Szyszczak, 2011). Following the traditional classifications under Article 102 TFUE, exclusive control of research-valuable information by a dominant company is prohibited under competition law when it gives rise to exploitative or exclusionary behaviours, ultimately hindering the rise of new innovative technologies (Colangelo and Borgogno, 2019).

With specific regards to exclusionary abuses stemming from the refusal to disclose research-valuable informational assets, the essential facilities doctrine under Article 102 TFUE has grounded the adoption by the CJEU of behavioural remedies, mandating access to or disclosure of research-relevant information (Waller, 2012; Newman, 2014).

Traditionally, the essential facilities doctrine, and the related sharing remedies, has been regarded as applicable to exclusionary abuses under Article 102 TFUE in 'exceptional circumstances'. These were first defined in 
the Magill $^{9}$ and IMS Health ${ }^{10}$ cases, which set a specific test for the assessment of the abusiveness of a refusal to license an intellectual property under Article 102 TFUE. 11

Relevant factors for these purposes were related to 1) the indispensable nature of the refused product or service for the exercise of a particular business in a downstream market; 2) the exclusion of effective competition in the considered market as a result of the refuse; 3 ) the prevention of the development of a new product for which there is consumer demand; and ultimately iv) the unjustified nature of the refusal (Drexl, 2017).

With regards to the essential nature of the requested facility, the Magill decision has specified that the refusal to give access to a facility amounts to an abuse when the facility is an 'indispensable raw material' for the provision of a derivative service or product. ${ }^{12}$ In particular, in the Bronner case, ${ }^{13}$ it was stressed how the requirement of indispensability attains to the fact that it is not economically viable for the competitor to autonomously reproduce a facility that is comparable in scope to that held by the dominant company. ${ }^{14}$ According to the Bronner decision, thus, access to the facility is not indispensable if alternatives are available, although they are less valuable.

The consideration of the peculiar effects generated by refusals to disclose research-valuable information on innovation has led to a progressive reconsideration of the essential facilities doctrine's requirements in the context of innovation markets (Graef, 2019). The focus of the analysis for the purposes of an infringement of Article 102 TFUE appears to have thus shifted from the consideration of the occurred exclusion or restriction of effective competition, ${ }^{15}$ to the consideration of a potential restriction on future innovation. Also the new product requirement (Houdijk, 2005), ${ }^{16}$ has been expansively interpreted, by referring it to the research process as such. In this respect, the IMS Health decision has for the first time considered the possibility that the essential facility doctrine could be applied also with reference to a "potential or even

9 CJEU judgment of 6 April 1995, Joined cases C-241/91 and C-242/91 Radio Telefis Eireann (RTE) and Independent Television Publications Ltd (ITP) v Commission, ECLI:EU:C:1995:98.

10 CJEU judgment of 29 April 2004, C-418/01 IMS Health GmbH \& Co. OHG v Commission, ECLI:EU:C:2004:257.

11 C-241/91 and C-242/91 Magill, para. 56; C-418/01 IMS Health.

12 Joined cases C-241/91 and C-242/91 Magill, para. 52.

13 CJEU judgment of 26 November 1998, C-7/97 Oscar Bronner GmbH \& Co. KG v Mediaprint Zeitungs, ECLI:EU:C:1998:569.

14 C-7/97 Oscar Bronner, paras. 43-46, para. 38.

15 ECJ judgment of 6 March 1974, Joined cases C-6 and 7/73 Istituto Chemioterapeutico Italiano S.p.A. and Commercial Solvents Corporation v Commission, ECLI:EU:C:1974:5, para. 25; C-241/91 and C-242/91 Magill, para. 56; C-418/01 IMS Health, para. 52.

16 C-241/91 and C-242/91 Magill, para. 54; C-418/01 IMS Health, paras. 48-49. 
hypothetical market for the asset required, provided that there is an actual demand for [the asset] on the part of undertakings which seek to carry on the business for which they are indispensable'. ${ }^{17}$

The approach to the essential facility doctrine appears to have broadened in the Microsoft case, ${ }^{18}$ where the restrictive approach to the indispensability requirement expressed in the Bronner case has been substantially broadened and linked to the fact that, thanks to the access to the essential facility, the requesting undertaking would have been able to compete with the incumbent 'on an equal footing' for the development of a new product. ${ }^{19}$

Moreover, the General Court lowered the anticompetitive threshold down to the existence of the likelihood that the refusal to access the facility would 'eliminate all effective competition on the market', ${ }^{20}$ this leading to a 'limitation not only of production or markets, but also of technical development'. ${ }^{21}$ More precisely, the General Court highlighted that the restriction of technical development was not only to be suffered on the side of the company receiving the refusal, but also on the side of the same incumbent, whose refusal would have consolidated its dominant company, ultimately leading to a decrease of the same incumbent's incentives to innovate. ${ }^{22}$ The reference to technical development signals the first application of the essential facilities doctrine to innovation markets, irrespective of the definition of a product or service that is meant to be developed by the company who requests access to relevant information.

Interestingly, this broad conception of the new product requirement has been expressly acknowledged by the Commission Guidance on enforcement priorities under Article $82 \mathrm{EC}$, stressing that 'harm can be caused to consumers when the competitors that the dominant undertaking forecloses cannot, as a result of the refusal to introduce to the market innovative products or services and/or where follow-on innovation is likely to be stifled'. ${ }^{23}$ As the Commission affirms, this harm is especially likely to occur when the business in need of supply (...) intends to produce new or improved products or services for which there is potential consumer demand or is likely to contribute to technical progress'. ${ }^{24}$ These statements by the Commission ultimately appear to pose

\footnotetext{
17 C-418/01 IMS Health, paras. 44-45, 49.

18 CFI judgment of 17 September 2007, Case T-201/04 Microsoft Corp. v Commission, ECLI:EU:T:2007:289.

19 T-201/04 Microsoft, para. 421.

20 T-201/04 Microsoft, para. 563.

21 T-201/04 Microsoft, para. 647.

22 T-201/04 Microsoft, paras. 697-698.

23 European Commission Guidance on Enforcement Priorities in Applying Article 82 of the EC Treaty to Abusive Exclusionary Conduct by Dominant Undertakings, OJ C 45, 24.2.2009, p. 7-20, para. 87.

${ }^{24}$ Ibidem.
} 
grounds for a new justification of the essential facility doctrine, working as a means to establish a level playing field for research and innovation through targeted sharing remedies.

\section{The divestment of research pools in merger procedures}

Innovation considerations have lately been given particular attention by the Commission in the context of mergers in the pharmaceutical market, and also in the neighbouring chemical market. In the Medtronic/Covidien merger, ${ }^{25}$ the Commission found that the merger between the two medical devices producers would have restricted competition, and thus diminished the level of innovation in the considered market, disincentivizing one of the parties to finish the testing procedures for the promising drug Stellarex. Likewise, also in the acquisition by Novartis of the company Glaxosmithklines' (GSK) oncology business, ${ }^{26}$ the Commission detected the risk that the merger would have stopped developing two important drugs for the cure of skin and ovarian cancer, thus negatively impacting the market's innovation outcomes. A third similar case is to be found in the merger involving Pfizer and Hospira, ${ }^{27}$ which the Commission deemed to affect the development of an important biosimilar drug treating autoimmune diseases. Pfizer, who was carrying out the testing of such drug, would have indeed retarded the testing phases after the merger, or would have divested the research on the drug to the originator, thus hindering price competition. Ultimately, also in the merger between Johnson \& Johnson and Actelion, ${ }^{28}$ the Commission noted the risk that one of the two parallel projects for the development of a new insomnia drug would have been abandoned after the merger, thus, as in the previous cases, impairing innovation competition (European Commission, 2019).

The mentioned cases are particularly relevant because they signal an increasing use of the innovation market paradigm within pharmaceutical sector enquiries. This orientation has been reaffirmed by the Commission also in other mergers in the neighbouring chemical sector, as in the Dow/ DuPont ${ }^{29}$ and in the Bayer/Monsanto ${ }^{30}$ cases where, just as in the mentioned pharmaceutical cases, the merger between research-based companies was

\footnotetext{
25 Commission decision of 28 November 2014, Case Comp/M.7326 Medtronic/Covidien.

26 Commission decision of 28 January 2015, Case Comp/M.7275 Novartis/Glaxosmithkline Oncology Business.

27 Commission decision of 4 August 2015, Case Comp/M.7559 Pfizer/Hospira.

28 Commission decision of 9 June 2017, Case M.8401 Johnson \& Johnson/Actelion.

29 Commission decision of 27 March 2017, Case M.7932 Dow/DuPont.

30 Commission decision of 21 March 2018, Case M.8084 Bayer/Monsanto.
} 
investigated from the perspective of the impact on the development of new products (Ibáñez Colomo, 2018).

In all the considered mergers, the Commission forecasted an overall reduction in innovation efforts, substantiated in a decrease of the number and quality of new products, directly resulting from the 'discontinuation, deferment or redirection of competing lines of research and early pipeline products'. ${ }^{31}$ Similarly to the above-cited essential facilities cases under Article 102 TFUE, also in these merger cases, it appears that the Commission has directly reacted against the threats given by information accumulation, occurring in mergers as a result of the combination of two companies' research divisions. This has been done through the approval of the assessed mergers upon the condition that specific remedies were enacted by the merging parties.

In these regards, for example, in the Medtronic/Covidien merger, Medtronic committed to sell Covidien's Stellarex business, including manufacturing equipment, related intellectual property rights as well as scientific and regulatory material needed to finish the drug's development. Similarly, in Novartis/GSK Oncology Business, Novartis committed to divest one R\&D business related to one of the two considered drugs to a third company, and retransfer the $R \& D$ business of the other drug to the same company that was the original licensor. In addition to this, the remedy envisaged a cooperation agreement between this company and another third party, securing the proper testing procedures for the two drugs enabled by such cooperation. Also, in the Pfizer/Hospira case and in the Johnson \& Johnson merger with Actelion, the remedies were related to the divestment of the biosimilar drug's development to third companies.

Overall, thus, the mentioned commitments are specifically designed to assure the protection of innovation and so to preserve the ability and incentives to innovate, with that restoring effective competition in innovation. These commitments mostly assure that pipeline projects regarding important drugs are not abandoned and that these are taken up by a third operator (European Commission, 2019), acting as a new innovative competitor posing competitive constraints to preserve innovation (De Coninck, 2016).

More precisely, commitments regarding the divestment of research pools appear to imply exactly the sharing of research-valuable information to competitors actually or potentially acting within the same research field, together with the needed technological research infrastructure. The establishment of additional cooperation agreements is, thus, supposed to maximize the research expertise available in the market and so to foster innovation.

31 Case M.7932 Dow/DuPont, para. 277. 
In this perspective, the commitment to divest research pools can be read as an indirect means to impose onto merged entities pro-competitive information sharing obligations directed to other players in the same research market. They thus reflect how competition enforcement can open up concentrated research pipelines through the sharing/aggregation of different technological assets for the preservation of efficiency goals in a given innovation sector (Aghion et al., 2005).

\section{Can information-based remedies be applied to data silos?}

\section{Introduction}

The study has so far demonstrated the emergence, at European competition enforcement level in high technology markets, of remedies requiring either abusing dominant undertakings or merging entities the disclosure of researchrelevant information to actual or also potential competitors. As has been argued, both disclosure obligations to disclose 'essential' information under Article 102 TFUE and commitments regarding the divestment of research pools to competing research actors, can be interpreted as special sectorspecific sharing obligations established by competition authorities.

Framed in these terms, the question arises whether competition authorities could impose similar sharing obligations in the context of digital markets. In this regard, the European Commission has stated that general competition law is applicable in respect to data-driven business models. Its remedies can thus be invoked to claim wider access to data held by a single market player. ${ }^{32}$ In this respect, the refusal to grant access to essential business data has been acknowledged by the Commission as one of the principal unfair trading practices on online platforms. ${ }^{33}$ Under these premises, the sharing remedy under the essential facilities doctrine has been expressly put in connection with the objectives of the free flow of information in digital markets. ${ }^{34}$ Similarly, also regarding mergers implying the combination of different datasets, the risks of an excessive market concentration resulting from digital data aggregation, and leading to market foreclosure, have been highlighted in the course of merger procedures. ${ }^{35}$ Also in these cases, there have been commitments by

\footnotetext{
32 See: Commission Staff Working Document on the Free Flow of Data.

33 Commission decision of 23 February 2016, Case M.7813 Sanofi/Google/DMI JV.

34 European Commission, Communication - Building a European Data Economy.

35 Case M.7813 Sanofi/Google/DMI JV.
} 
the merging parties to open up, and thus to share, their datasets to other third-party service providers. ${ }^{36}$

These policy stances appear to uphold the opportunity given by informationbased remedies to aliment competition in data-driven research and with that the otherwise compromised well-functioning of digital innovation markets. If applied to the case of data pools, these competition remedies could indeed attract otherwise foreclosed entities to the innovation process, in cases where the data holder has gained a level of market power that entrenches the same incumbent on the 'technological frontier' (Lillà Montagnani, 2006) in a way that blocks the innovation pace in a given sector.

However, the extension of such information-based remedies in the context of digital markets is highly debated (Lindqvist, 2016; Drexl, 2017). The concerns that are being highlighted by the literature appear to be twofold, of both theoretical and operational nature.

\section{The theoretical perspective and data silos' specificities}

Some of the challenges, associated with the enactment of competition enforcement remedies for the purposes of data sharing promotion, regard the 'para-regulatory' nature of these remedies (Maggiolino, 2015). This critique is not new and has traditionally been associated with disclosure obligations envisaged under the essential facilities doctrine (Lao, 2013; Abrahamson, 2014; Meadows, 2015). It highlights the re-allocative, and thus market-shaping, effect of these remedies (Geradin, 2004; Monti, 2008; Weber, 2015).

In this respect, it has been observed that the proactive imposition by a competition authority of disclosure duties, onto a dominant company or a merging party, is an operation of outright market design: the imposition of a sharing remedy would be a means to accomplish distributive justice goals, through the surreptitious creation of a level playing field. ${ }^{37}$ The use of competition enforcement in this sense would thus amount to a form of interventionist market regulation (Graef, 2019).

These considerations certainly signal the need to restrict the employment of proactive information-based remedies, in consistency with competition law's traditional role of correcting businesses' active behaviour instead of interfering with the same businesses' contractual freedom ${ }^{38}$ and with their

\footnotetext{
36 Commission decision of 6 December 2016, Case M.8124 Microsoft/Linkedin.

37 CJEU judgment of 6 November 2012, Case 551/10 Editions Odile Jacob v. Commission, ECLI:EU:C:2012:681, paras. 66-67.

38 CPI judgment of 26 October 2000, Case T-41/96 Bayer v. Commission, ECLI:EU:T:2000:242, para. 180 .
} 
right to property, in case the requested informational asset is protected. ${ }^{39}$ However, although still relevant in the context of digital markets, the abovehighlighted limits to the scope of competition law enforcement may be slightly shifted in the view of the specific market features of digital markets.

Digital businesses' market position is indeed sustained and ultimately entrenched by network effects, high switching costs and lock-in effects. Incumbents are thus facilitated to enter connected technological markets and to engage in 'conglomerate strategies' (Graef, 2019), through which they partner or acquire new potential market entrants (Kathuria, 2019). The peculiar dynamics, in which competition in digital markets proceed, also enable market tipping conducts in multisided markets, which exacerbate the unavailability of research-valuable resources. The weak markets' self-correcting mechanisms thus ultimately risk impairing the development by other market players of innovative technologies (Graef, 2019).

Under these premises, a 'behavioural' competition intervention would be thus justified when the phagocyting dynamics of data-driven markets themselves appear to be incapable of self-corrective reactions against occurred antitrust harms. In these exceptional cases, information sharing remedies would meet the objective of restoring the effective functioning of data-driven markets, in consistency with the latest European policies with free-flow of information objectives.

\section{The operational perspective and the relevance of data protection law}

\subsection{Opening remarks}

The theoretical justification of the application of information-based remedies to the case of data silos in digital markets does not displace the emerging doubts regarding the administrability of data sharing competition remedies. Recent scholarship has been thus questioning the feasibility of considering data as a facility object of a specific duty to deal.

In this regard, it has been argued that digital data would not be eligible as an essential facility precisely because it can be easily replicated and is thus never really 'essential' for the development of a new product or service (Maggiolino and Colangelo, 2017). However, this argument specifically relates to general big data, as search engine data or social network data, that is, general runaway data, and not to more sophisticated types of digital data as digital health data or other more sector-specific data as financial data

39 C-7/97 Oscar Bronner, para 56. 
(Kathuria, 2019). Nonetheless, the assessment by competition authorities regarding the existence of an anticompetitive harm, directly resulting from the exclusive control of datasets and the related impairment of innovation courses, can prove to be particularly burdensome.

Further difficulties relate to the ex ante definition of which exact datasets need to be made the object of the sharing obligation (Maggiolino and Colangelo, 2017; Kathuria and Globocnik, 2019). In this respect, it is questioned whether the disclosed or divested data pools should concern previously defined datasets, or whether these should be updated in accordance to the pace of data analytics. In addition to this, competition authorities have to face the problem of defining the purpose for which access to certain datasets is given (Maggiolino and Colangelo, 2017). Also the timeframe set for the sharing remedy should be carefully determined, also in light of the risk that, by granting access to an excessively large dataset, the same competitors could be disincentivized from generating their own research data (Kathuria and Globocnik, 2019).

All these difficulties render the enactment by competition authorities of sharing obligations regarding digital data a highly discretionary matter, to the detriment of legal certainty in competition enforcement. Partial solutions to these problems could, nonetheless, be found in the interaction between competition policy regarding data sharing remedies and the European data protection framework under the General Data Protection Regulation. Data protection rules, as defined under the General Data Protection Regulation, could indeed be relevant for addressing the highlighted shortcomings both related to the assessment of the existence of anticompetitive harm and to the design of such specific sharing obligations. As will be argued below, these concerns could be partly addressed through a collaborative effort between competition and data protection authorities.

\subsection{The collaborative governance of data sharing remedies}

The interaction between data protection and competition authorities for the purposes of competition enforcement in the digital economy had already been advocated in the joint statement released in 2016 by the German and French competition authorities (Autorité de la concurrence and Bundeskartellamt, 2016). This was reaffirmed also by the European Data Protection Board, which has pointed out that the 'data protection and privacy interests of individuals are relevant to any assessment of potential abuse of dominance as well as mergers of companies, which may accumulate or which have accumulated significant informational power' (European Data Protection Board, 2018). For the purpose of the authorities' reciprocal support, the Digital Clearinghouse already provides 
a basic forum for the evaluation of the interplay between data protection law and competition policy vis à vis digital technologies (Vezzoso, 2020).

From a general perspective, the specific countenance of the collaboration between data protection and competition authorities will largely depend on the degree of interplay between data protection law and competition enforcement that each scrutinised case triggers. In this respect, the German Facebook case so far represents the most thought-provoking example of the infiltration of data protection considerations into competition assessments, directly resulting from the convergence between the competition and data protection frameworks in digital markets (Schneider, 2018). The Bundeskartellamt (2019) first and then later the Düsseldorf court ${ }^{40}$, have differently assessed data protection law violations for the evaluation of competition-based abuses (D'Cuhna, 2019). For the purposes of the investigation, the Bundeskartellamt has involved the German data protection authority, the German consumer protection authorities as well as other national competition authorities (McLeod, 2016).

The Facebook case is regarded as the leading benchmark regarding the interaction between data protection law and competition policy, from both a substantial and an institutional standpoint. However, the specific case of data silos, and resulting sharing remedies, appear to open up an array of further and still largely unexplored synergies between the considered frameworks and the concerned independent authorities.

The first synergy regards the opportunity for competition authorities to exploit information regarding the involved undertakings' accumulated data - both in terms of nature and of the structuring of the data, which data protection authorities are entitled to access under the General Data Protection Regulation. The idea is increasingly considered also by literature, which has evaluated the opportunity of a closer collaboration between the concerned authorities in real-life investigations, especially in respect to the information they possess, in order to avoid duplication of efforts and to facilitate their respective tasks (D'Cuhna, 2019).

Under the GDPR, data protection authorities have strong enquiring powers grounded in Articles 30, 35, 36(1) and 58(1)(b) GDPR. In accordance to Article 36(1) GDPR, businesses have the obligation to consult the supervisory authority prior to the processing, when the data protection impact assessment shows that the processing would result in a high risk, in the absence of measures to mitigate the risk. For the purposes of this prior consultation, the controller shall provide the supervisory authority with the data protection impact assessment performed under Article 35 GDPR, together with any other

40 Judgment of the Düsseldorf Court of Appeal of 26 August 2019, Case VI-Kart 1/19 (V). 
information requested by the same supervisory authority, as the one contained in businesses' records of processing activities required by Article 30 GDPR.

Moreover, Article 58(1)(e) GDPR establishes data protection authorities' power to carry out investigations in the form of data protection audits, enabling the same data protection authorities to access 'all personal data' and 'all information necessary for the performance of its tasks' (Article 58(1)(e) GDPR). Through their investigative powers, data protection authorities can enquire which data are the objects of processing activities, and how exactly they are technically processed. Accordingly, they can access the most detailed information regarding the content and structure of data pools (Casey, Farhangi and Vogl, 2019).

In light of this data protection framework, it appears that the information available to data protection authorities could be extremely relevant for guiding and substantiating competition authorities' assessment over the identification of harm to innovation in a given market resulting from data concealment, over the types of data that has been pooled and then enclosed in the relevant innovation sector and, thus, over the essential nature of a specific dataset. The same information could be equally relevant for the definition of the terms of a sharing remedy, namely the definition of the data that needs to be made the object of the remedy and the timeframe that the sharing remedy has to cover.

However this informational collaboration between the two authorities could find a significant obstacle precisely in the limitation of supervisory authorities' competences only to the processing of personal data and the protection of data subjects' privacy. Hence, the legal admissibility of supervisory authorities to execute their investigative powers, in order to achieve goals other than the ones directly related to data protection, could be questioned.

However, these legitimacy doubts are to be overcome in case these investigative powers are ordinarily enacted by data protection authorities within the realm of their competences, that is, for the purposes of the protection of natural persons' right to data protection. The fact that the so retrieved information about a company's datasets is further employed by a competition authority for the purposes of its tasks, does not amount to stretching of neither of the considered authorities' competences.

This has been confirmed by the European Data Protection Board, which has welcomed the support given to competition authorities by data protection authorities in the assessment of 'conditions or remedies for mitigating negative impacts on privacy and other freedoms' and has stated that data protection authorities' assessment can be also 'integrated into the analysis carried out by competition authorities during their assessment under competition law' (European Data Protection Board, 2018). From a further perspective, the exchange of information between different authorities has been interestingly 
considered by the European Commission, where the sharing of data among public authorities has been identified as a key policy action within the European Strategy for data, for it reduces the administrative burdens on companies operating within the single market (European Commission, 2020).

A second source of synergy directly relates to the design of data sharing remedies. This synergy arises when the data made the object of the sharing remedy are personal data. In this case, the imposition of sharing remedies regarding research data implies the transfer by the data holder to a third party and thus the further processing of this personal data. As a result, in designing the sharing remedies needed to open up established data pools, competition authorities should conform the sharing remedies to the specific data protection rules set by the General Data Protection Regulation.

The first design concern, regarding sharing remedies involving personal data, relate to the identification of a lawful basis for the processing. In light of the difficulties of retrieving consent from interested data subjects as required under Article 6(1)(a) GDPR, the suitability of the legal basis regarding compliance with a legal obligation under Article 6(1)(c), to which the controller would be compliant in accordance to a competition authority's decision, has been questioned (Graef, Tombal, Streel, 2019). The interpretative uncertainties, regarding the possibility to include within the notion of legal obligation a decision by a competition authority, have suggested to consider the 'legitimate interest' basis under Article 6(1)(f) GDPR as the most suitable legal basis. The concerned legitimate interests would be precisely related to the compliance with a competition authority's decision in order to avoid the imposition of a fine (Graef, Tombal, Streel, 2019).

Similarly, also from the data recipients' perspective, the legitimate interest could be a relevant legal basis in consideration of the very rationale of data sharing remedies, which are imposed by competition authorities for the purposes of feeding otherwise impaired innovation processes. In this light, the data holder's legitimate interest could be directly related to research and innovation objectives. These objectives have a 'privileged position' within the same General Data Protection Regulation that, under recital 159 GDPR, links them to the broader goals under Article 179(1) TFUE, directly related to the strengthening of the scientific and technological progress within the internal market. Processing activities for research purposes enjoy a special data protection regime, facilitating data controllers' processing through the possibility to derogate to the general data protection principles, that is, the principle of purpose limitation under Article 5(1)(b) GDPR and storage limitation under Article 5(1)(e) GDPR and to data subjects' rights as the right to be forgotten under Article 17(3) GDPR and the right to be informed under Article 14(5) GDPR. For the counterbalance of these derogations, Article 89(1) 
GDPR requires data controllers to enact safeguards, assuring the respect of fundamental data protection principles, as the principle of data minimization, and providing 'appropriate' technical and organisational measures for the protection of data subjects' rights and freedoms. The appropriateness of these safeguards will have to be considered in light of the specificities of the newly formed data pool. Although the choice of these safeguards is left to the data recipient/controller in accordance with the principle of accountability, it could be desirable that in designing the sharing remedies, competition authorities already set a minimum data protection standard to be respected for the research activities that the sharing remedy encourages.

The definition both of the lawful basis of the data transfer object of the data sharing remedy, and the safeguards to be enacted by the data recipient, require the necessary involvement of data protection authorities. These would thus be applying data protection rules and defining appropriate data protection thresholds in consistency with their tasks. Conversely, competition authorities' competences would not be circumvented, as long as the consideration and the compliance with data protection rules is directly functional to the enforcement of competition rules and not other rules (Reyna, 2020). In this perspective, the proposed collaboration between competition and data protection authorities would reconcile innovation objectives underlying data sharing remedies with an adequate protection of data subjects' fundamental right to data protection (Drexl, 2018; Gal-Aviv, 2020).

\section{Conclusions}

The competition remedies developed under the latest interpretations of the essential facilities doctrine and under commitment decisions in the pharmaceutical markets, set case-specific obligations exceptionally designed by competition authorities targeting either dominant or merged research entities, respectively as a result or in forecast of an identified antitrust harm. The analysis has demonstrated the relevance of both these information-based remedies for the opening up of formed data silos, and the pro-competitive design of businesses' data pools in digital markets.

The existence of specific market failures, and the reliance of data protection authorities' knowledge regarding the organisation and the object of existing data pools, have been identified as relevant limits for competition authorities' proactive intervention into businesses' data sharing practices.

Upon these conditions, the study demonstrates that competition law can intervene setting ex post remedies into formed data pools, rendering the 
competition process evolving around the formed research pools more respectful of the competing parties' freedom to conduct research. However, in order to prevent an undue proactive market structuring effect through information sharing remedies, these should be strictly circumscribed to the elimination of the consequences of the anticompetitive behaviour. In respect to data sharing remedies, also and especially, competition authorities should bear in mind the CJEU precept, requiring behavioural remedies to be circumscribed to the provision of 'advantages which have been wrongfully withheld'. ${ }^{41}$

For the purposes of the design of data sharing remedies, the study has suggested the opportunity of a stricter collaboration between data protection and competition authorities. The proposed cooperation between the two authorities would render traditional information-based remedies under European competition law more adherent to the specificities of emerging data silos as mostly made up of personal data.

The reliance on data protection authorities' expertise would help to fill some of the highlighted administrability loopholes, supporting competition authorities' case by case assessment regarding when a sharing remedy is functional to the re-establishment of the effective functioning of the market harmed as a result of businesses' anticompetitive conduct. It would thus help competition authorities identify when and how competition enforcement can intervene by setting sharing remedies over formed data pools in highly networked data-driven innovation sectors.

In this perspective, it is argued that traditional information-based remedies shall be applied to data silos and, thus, interfere with free digital market forces, only within the strict realm of competition and data protection rules. Only within these limits, European competition law and its remedies can thus become an additional policy tool for the pursuing of data sharing and innovation objectives in the internal market, in consistency with the European strategy for data.

\section{Literature}

Abrahamson, Z. (2014). Essential Data, The Yale Law Journal, 124, 3, 867-881.

Aghion, P. et al. (2005). Competition and Innovation: an Inverted-U Relationship, The Quarterly Journal of Economics, 120, 2, 701-728.

Autorité de la concurrence and Bundeskartellamt (2016). Competition Law and Data.

Retrived from: https://www.bundeskartellamt.de/SharedDocs/Publikation/DE/Berichte/

${ }^{41}$ C-6 and 7/73 Commercial Solvents, para.45. 
Big\%20Data\%20Papier.pdf;jsessionid=ACA3FB70B94AE185F0F4B07263976551.2_ cid378? _blob $=$ publicationFile $\& v=2(30.06 .2020)$.

Bamberger, K.A., Lobel, O. (2017). Platform Market Power, Berkeley Technology Law Journal, 32, 1052-1092.

Bundeskartellamt (2019). Bundeskartellamt Prohibits Facebook From Combining User Data From Different Sources. Retrived from: https://www.bundeskartellamt.de/SharedDocs/ Meldung/EN/Pressemitteilungen/2019/07_02_2019_Facebook.html (30.06.2020).

Casey, A., Farhangi, A., Vogl, R. (2019). Rethinking Explainable Machines: The gdpr's "Right to Explanation" Debate and the Rise of Algorithmic Audits in Enterprise, Berkeley Technology Law Journal, 34, 145-188.

Colangelo, G., Borgogno, O. (2019). Data Sharing and Interoperability: Fostering Innovation and Competition Through APIs, Computer Law \& Security Review, 35, 5, 1-17, https://doi.org/10.1016/j.clsr.2019.03.008

Crémer, J., De Montjoye, Y.-A., Schweitzer, H. (2019). Competition Policy For the Digital Era - Final report, Report by the special advisers of Commissioner Vestager. Retrieved from: http://ec.europa.eu/competition/publications/reports/ kd0419345enn. pdf (30.06.2020).

David, P. (2000). The Digital Technology Boomerang: New Intellectual Property Rights Threaten Global Open Science, Stanford Department of Economics Working Paper N. 00-006. Retrieved from: https://ideas.repec.org/p/wpa/wuwpdc/0502012.html (30.06.2020).

D'Cuhna, C. (2019). In Memory of Giovanni Buttarelli, International Data Privacy Law, 9, 3, 129-131.

De Coninck, R. (2016). Innovation in EU Merger Control: In Need of a Consistent Framework, Competition Law \& Policy Debate, 2, 3, 41-51.

Drexl, J. (2017). Designing Competitive Markets For Industrial Data: Between Propertization and Access, Journal of Intellectual Property and Information Technology and Electronic Commerce Law, 257-292.

Drexl, J. (2018). Data Access and Data Control in the Era of Connected Devices, Study on Behalf of the European Consumer Organisation BEUC. Retrieved from: https:// www.beuc.eu/publications/beuc-x-2018-121_data_access_and_control_in_the_area_of_ connected_devices.pdf (30.06.2020).

European Commission (2019). Report from the Commission to the Council and the European Parliament, Competition Enforcement in the Pharmaceutical Sector (2009-2017) - European Competition Authorities Working Together for Affordable and Innovative Medicines. Retrived from: http://ec.europa.eu/competition/sectors/ pharmaceuticals/report2019/index.html (30.06.2020).

European Data Protection Supervisor (2014). Privacy and competitiveness in the age of big data: The interplay between data protection, competition law and consumer protection in the Digital Economy. Retrieved from: https://edps.europa.eu/sites/edp/ files/publication/14-03-26_competitition_law_big_data_en.pdf (30.06.2020).

European Data Protection Board (2018). Statement of the EDPB on the Data Protection Impacts of Economic Concentration. Retrieved from: https://edpb.europa.eu/ourwork-tools/our-documents/autre/statement-edpb-data-protection-impacts-economicconcentration (30.06.2020).

Gal, M., Aviv, O. (2020). The Competitive Effects of the GDPR, https://papers.ssrn.com/ sol3/papers.cfm?abstract_id $=3548444$ 
Gardner, R., Ostrom, E., Walker, J.M.(1990). The Nature of Common-Pool Resource Problems, Rationality and Society, 2, 335-358, https://doi.org/10.1177/1043463190002003005

Geradin, D. (2004). Remedies in Network Industries: EC Competition Law vs. Sector-specific Regulation, Cambridge: Intersentia.

Gervais, D. (2019). Exploring the Interfaces Between Big Data and Intellectual Property Law, JIPITEC, 10, 3, 1-17.

Graef, I. (2016). EU competition law, data protection and online platforms - Data as Essential Facility, Alphen aan den Rijn, Wolters Kluwer.

Graef, I., Husovec, M., Purtova, N. (2018). Data Portability and Data Control: Lessons from an Emerging Concept in EU Law, German Law Journal, 19(6), 1359 1398, https:// doi.org/10.1017/S2071832200023075

Graef, I. (2019). Rethinking the Essential Facilities Doctrine in Digital Markets, Revue juridique Thémis de l'Université de Montréal, 53, 1, 33-72.

Graef, I., Tombal, T., Streel, A. (2019). Limits and Enablers of Data Sharing: An Analytical Framework for EU Competition, Data Protection and Consumer Law, TILEC Discussion Paper DP 2019-024, https://papers.ssrn.com/sol3/papers.cfm?abstract_id=3494212

Hilty, R.M. (2018). Intellectual Property and Private Ordering. In: R. Dreyfuss, J. Pila (ed.), The Oxford Handbook of Intellectual Property Law, Oxford University Press: Oxford, 898-930.

Houdijk, J. (2005). The IMS Health Ruling: Some Thought on its Significance for Legal Practice and its Consequences for Future Cases such as Microsoft, European Business Organization Law Review, 6, 3, 467-495,https://doi.org/10.1017/S1566752905004672

Ibáñez Colomo, P. (2018). Competition Law and Innovation: Where Do We Stand?, Journal of European Competition Law \& Practice, 9, 9, 561-562, https://doi.org/10.1093/ jeclap/lpy074

Kathuria, V. (2019). Greed For Data and Exclusionary Conduct in Data-driven Markets, Computer Law Security \& Review, 35, 1, 89-102.

Kathuria, V., Globocnik J. (2020). Exclusionary Conduct in Data-driven Markets: Limitations of Data Sharing Remedy, Journal of Antitrust Enforcement, https://doi. org/10.1093/jaenfo/jnz036

Lao, M. (2013). Search, Essential Facilities, and the Antitrust Duty to Deal, Northwestern Journal of Technology and Intellectual Property, 11, 5, 276-319.

Lillà Montagnani, M. (2006). Predatory and Exclusionary Innovation: Which Legal Standard for Software Integration in the Context of the Competition versus Intellectual Property Clash?, The International Review of Intellectual Property and Competition Law, 37, 304-335.

Lindqvist, B. (2016). Big Data, Open Data, Privacy Regulations, Intellectual Property and Competition Law in an Internet of Things World - The Issue of Accessing Data, Stockholm Faculty of Law Research Paper Series N.1/2016 https://papers.ssrn.com/sol3/ papers.cfm?abstract_id=2891484, 16-181.

Maggiolino, M. (2015). The Regulatory Breakthrough of Competition Law: Definitions and Worries. In: J. Drexl and F. Di Porto (ed.), Competition Law As Regulation, Cheltenham: Edward Elgar, 3-26; https://doi.org/10.4337/9781783472598.

Maggiolino, M., Colangelo, G. (2017). Big Data as a Misleading Facility, European Competition Journal, 249-281.

McLeod, R. (2016). Novel But a Long Time Coming: the Bundeskartellamt Takes on Facebook, Journal of European Competition Law and Practice, 7, 6, 367-368. 
Meadows, M. (2015). The Essential Facilities Doctrine in Information Economies: Illustrating Why the Antitrust Duty to Deal is Still Necessary in the New Economy, Fordham Intellectual Property, Media \& Entertainment Law Journal, 25, 3, 795-830.

Monti, G. (2008). Managing the Intersection of Utilities Regulation and EC Competition Law, Competition Law Review, 4, 2, 123-145.

Newman, N. (2014). Search, Antitrust and The Economics of the Control of User Data, Yale Journal of Regulation, 31, 2, 402-454.

OECD (2019). Enhancing Access to and Sharing of Data: Reconciling Risks and Benefits for Data Re-Use Across Societies. Retrieved from: https://www.oecd-ilibrary.org/ sites/276aaca8-en/index.html?itemId=/content/publication/276aaca8-en

Purtova, N. (2015). The Illusion of Personal Data as No One's Property, The Illusion of Personal Data as No One's Property, Law, Innovation and Technology, 7, 1, 83-111.

Reyna, A. (2020). Optimising Public Enforcement in the Digital Single Market Through Cross-institutional Collaboration, https://papers.ssrn.com/sol3/papers.cfm?abstract_ $\mathrm{id}=3529198$

Rubinfeld, D., Gal, M. (2017). Access Barriers to Big Data, Arizona Law Review, 59, 340-381.

Rubinfeld, D., Gal, M. (2019). Data Standardisation, New York University Law Review, 94, 737-770.

Schneider, G. (2018). Testing Art. 102 TFUE in the Digital Marketplace: Insights from the Bundeskartellamt's Investigation Against Facebook, Journal of European Competition Law and Practice, 9, 4, 213-225.

Schneider, G. (2019). Disentangling Health Data Networks: A Critical Analysis of Arts 9(2) and 89 GDPR, International Data Privacy Law, 9(4), 253-271.

Svetiev, Y. (2007). Antitrust Governance: the New Wave of Antitrust, Loyola University Chicago Law Journal, 38, 595-694.

Szyszczak, E. (2011). Controlling Dominance in European Markets, Fordham International Law Journal, 33, 6, 1738-1775.

Tombal, T. (2020). GDPR as a Shield to a Data Sharing Remedy, Working paper presented at the CPDP 2020 Conference - Junior Academic Session. Retrieved from: https://papers. ssrn.com/sol3/papers.cfm?abstract_id=3516718 (30.06.2020).

Vestager, M. (2016). Big Data and Competition. Retrieved from: https://wayback.archive-it. org/12090/20191129222113/https://ec.europa.eu/commission/commissioners/2014-2019/ vestager/announcements/big-data-and-competition_en (30.06.2020).

Vezzoso, S. (2020). All Happy Families are Alike: The EDPB's Bridges Between Competition and Privacy. Retrieved from: https://papers.ssrn.com/sol3/papers.cfm?abstract_ $\mathrm{id}=3519974(30.06 .2020)$.

Waller, S.W. (2012). Access and Information Remedies in High-Tech Antitrust, Journal of Competition Law and Economics, 8, 3, 575-593, https://doi.org/10.1093/joclec/nhs015

Weber, R.H. (2015). From Competition Law to Sector-specific Regulation in Internet Markets? A Critical Assessment of a Possible Structural Change. In: J. Drexl and F. Di Porto (ed.), Competition Law As Regulation, Cheltenham: Edward Elgar, 239-267, https://doi.org/10.4337/9781783472598,

Zoboli, L. (2020). Fuelling the European Data Economy: A Regulatory Assessment of B2B Data Sharing. Retrieved from: https://papers.ssrn.com/sol3/papers.cfm?abstract_ $\mathrm{id}=3521194(30.06 .2020)$. 